\title{
Apoptosis in bone physiology and disease
}

\author{
David E Hughes, Brendan F Boyce
}

Bone is typically thought to provide support for muscles and protection for vital organs but to be rather inactive at the cellular level. Thus, the concept of cell death in bone being of any importance to the physiology or pathology of this tissue, at first glance, may seem strange. However, the reality is that bone is a dynamic tissue the cells of which are involved in complex interactions with one another and with haemopoietic and stromal cells in bone marrow in a process that continually remodels the skeleton. Our current understanding is that two classes of cells are involved in this process, osteoclasts, which resorb bone matrix, and osteoblasts, which synthesise new bone matrix. These two families of cells interact at sites in bone where turnover is actively occurring at locations in periosteal, endosteal trabecular, and cortical bone. These sites are referred to as basic multicellular units (BMU). Within each BMU bone is resorbed by osteoclasts that then disappear and are replaced by osteoblasts which resynthesise bone, some becoming incorporated in the bone matrix to become osteocytes. This sequence of cellular events is described extensively elsewhere. ${ }^{12}$

There are several situations under which cell death may occur in bone as a physiological event (table 1). Probably the best recognised of these is during ossification of the growth plate. Hypertrophic chondrocytes disappear as growth plate cartilage calcifies and is resorbed from the primary spongiosa. Recent evidence has suggested that hypertrophic chondrocytes undergo apoptosis at this site. ${ }^{3}$ As the balance of evidence suggests that osteoclasts usually disappear at the cessation of their resorptive activity, it would seem likely that they undergo some form of cell death. In addition, it is conceivable that regulation of numbers of osteoclast precursors through induction of cell death may represent a mechanism by which the number of mature osteoclasts at any site is controlled. Whether cell death is an important event in the control of the activity of the osteoblast lineage is more difficult to gauge. From a theoretical perspective, it is possible that the number of mature osteoblasts that form in any BMU depends upon the balance of mitosis and apoptosis of their marrow stroma derived precursors. Also, although there are two well defined fates for osteoblasts (differentiation into osteocytes or lining cells), it is also possible that some osteoblasts undergo cell death. The remainder of this article provides an overview of what is currently known about cell death in the osteoclast and osteoblast lineages, and how the death of these cells may be of relevance to clinically important bone diseases.
Cell death: general considerations

Cell death is a surprisingly complex process that has received much study during the 1990 s, having being all but ignored during the $\frac{\bar{D}}{\bar{D}}$ previous century. In simple terms, cells can be $\underset{\mathbb{D}}{\overparen{D}}$ murdered (necrotic cell death) or commit sui- $\frac{\square}{q}$ cide (apoptotic cell death). The complexities of के cell death have been eloquently reviewed $\overrightarrow{0}$ elsewhere, ${ }^{45}$ and the distinction between $\overrightarrow{\vec{\omega}}$ necrotic and apoptotic cell death is becoming ${ }_{0}^{\omega}$ increasingly familiar to the general scientific audience. Apoptosis represents the "physio- 0 logical" mode of cell death and is therefore of relevance to the normal cellular events of bone. The important characteristics of apoptosis are: $N$ (1) apoptosis consists of a fairly stereotyped 음 sequence of morphologically recognisable events;

(2) apoptosis is controlled from within the cell by a large number of regulatory factors, but can $\vec{\theta}$ be induced or inhibited by external factors $\stackrel{?}{v}$ through receptor mediated mechanisms.

\section{Osteoclast apoptosis}

REGULATION OF OSTEOCLAST ACTIVITY

The osteoclast is a rare and elusive cell. Osteo- $\stackrel{D}{\square}$ clasts can be found at any of the million or so을 active remodelling sites that exist at any one $\vec{J}$ time in the adult human skeleton, but occupy a very small proportion of the total bone surface. The osteoclast is extremely rapid and effective in destroying bone matrix, therefore its activity: has to be tightly regulated to maintain normal: skeletal homeostasis. The potentially disas-응 trous consequences of loss of regulation of osteoclast activity are all too apparent in lytic을 bone diseases such as myeloma. The regulation $\frac{7}{0}$ of osteoclast formation and bone resorption has received considerable study (reviewed by Mundy and Roodman ${ }^{6}$ ). It is now well known N that osteoclasts are derived from haematopoi-N etic precursors that appear to be phenotypically ${ }_{\sigma}^{\omega}$ indistinguishable from the precursors of the monocyte/macrophage lineage until a very late $\frac{0}{\Phi}$ stage in their differentiation, at which time they@्? begin to acquire characteristics of adult (multi- $T$ nucleated, bone resorbing) osteoclasts such as $\overrightarrow{0}$

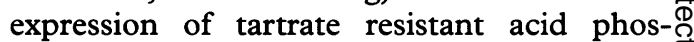
phatase (TRAP) and calcitonin receptors. The $\stackrel{\mathbb{1}}{\stackrel{1}{2}}$ proliferation and differentiation of the precursors is controllable by a wide range of factors $\Omega$ including systemic hormones such as parathy-응 roid hormone $(\mathrm{PTH}), 1,25$-dihydroxyvitamin $\mathrm{D}_{3}(1,25 \mathrm{D})$ and sex steroids, and cytokines $\frac{0}{2}$ growth factors such as granulocyte macrophage colony-stimulating factor (GM-CSF), macrophage-colony stimulating factor (MCSF), and interleukin (IL)-6. Mature osteoclasts are thought to lack receptors for most of the factors capable of stimulating or inhibiting 
Table 1 Cell death in bone physiology

\begin{tabular}{lll}
\hline Cell type & $\begin{array}{l}\text { Cell death has been } \\
\text { demonstrated }\end{array}$ & Cell death may occurt \\
\hline Growth plate chondrocytes & $\begin{array}{l}\text { During ossification of } \\
\text { hypertrophic zone }\end{array}$ & $\begin{array}{l}\text { As a mechanism for limiting } \\
\text { osteoblast recruitment } \\
\text { Osteoblast precursors }\end{array}$ \\
Osteoblasts & $\begin{array}{l}\text { At the cessation of bone } \\
\text { formation } \\
\text { Before bone resorption } \\
\text { At the initiation of resorption } \\
\text { As a mechanism for limiting } \\
\text { osteoclast recruitment }\end{array}$ \\
$\begin{array}{l}\text { Osteocytes } \\
\text { Osteoclast precursors }\end{array}$ & During the reversal phase of & \\
Osteoclasts & bone remodelling & \\
\hline
\end{tabular}

^Demonstrated in vivo in genetically normal animals; tspeculative possibilities, some of which have been suggested as interpretations or justifications for studies cited in this review.

their resorptive activity, ${ }^{78}$ but this is controversial, in part because of the lack of pure osteoclast cell preparations or cell lines. Experimental evidence suggests that once osteoclasts have formed and are resorbing bone, the resorptive activity of individual osteoclasts is controlled by soluble mediators produced by other cells, probably cells of the osteoblast lineage. ${ }^{78}$ However, another possible mechanism by which osteoclast activity could be controlled is by lengthening or shortening the lifespan of individual osteoclasts. As the majority of nucleated cells appears to possess the genetic programming to undergo programmed cell death (apoptosis), and that the apoptotic programme can be turned on or off by physiological stimuli, it is theoretically possible that osteoclast activity could be controlled through regulated apoptosis. For this to be the case, apoptosis would have to be the normal fate of the osteoclast.

\section{FATE OF THE OSTEOCLAST}

The fate of the osteoclast has been speculated upon intermittently for 100 years. The subject was reviewed in 1920 by Arey $^{9}$ who proposed that osteoclasts disappear from the bone surface after undergoing degenerative anatomical changes. More recently, the possible fates of osteoclasts during the reversal phase of bone remodelling were reviewed by Baron and co-workers ${ }^{2}$ who suggested that osteoclasts might undergo fission to form the mysterious macrophage-like cells that have been described at bone surfaces during reversal. Subsequently, Liu and co-workers ${ }^{10}$ studied the rapid loss of osteoclasts from the bone surfaces of calcium deficient rats following calcium repletion, and speculated that osteoclasts were undergoing cell death in this particular situation. Osteoclast apoptosis was first identified in vitro by Fuller and co-workers, who found that isolated rat osteoclasts underwent apoptosis if not treated with $\mathrm{M}-\mathrm{CSF},{ }^{11}$ and in vivo by Boyce and co-workers in a strain of transgenic mice. ${ }^{12}$ In these mice, SV40 T antigen was under the control of the TRAP promoter, resulting in abnormal proliferation of osteoclasts and their precursors. Rather than developing osteoporosis, as might be expected because of the increased numbers of osteoclasts, these animals developed osteopetrosis (increased bone density). Unexpectedly, many osteoclasts showed the morphological features of apopto- sis, an observation that was supported by a DNA strand end-labelling technique designed to detect the ends of DNA fragments resulting from the endonuclease activity characteristic of apoptosis. ${ }^{1314}$ These observations indicated that increases in osteoclast apoptosis may reduce bone resorption (hence the development of osteopetrosis in these mice) and raised the question of whether apoptosis might be a physiological event in the life cycle of the osteoclast. The question of the fate of normal osteoclasts was addressed by histological examination of calvarial bones from mice treated with local injections of recombinant IL-1. In this model, IL-1 causes intense, localised bone resorption that is followed by abrupt cessation of resorption and new bone formation several days after the cessation of IL-1 injections. ${ }^{15}$ Histological examination of bones taken on the fourth day after the last IL-1 injection revealed a very high proportion (up to $13 \%$ ) of osteoclasts showing the morphological features of apoptosis, namely loss of adhesion to the bone surface, cytoplasmic contraction and blebbing, nuclear chromatin condensation, and nuclear fragmentation. ${ }^{16}$ The osteoclasts showing these characteristics were very rarely situated at active resorption fronts, usually being at sites of reversal between areas of active resorption and active bone formation.

These observations strongly suggest that apoptosis is the normal fate of osteoclasts at reversal, and have subsequently been supported by a study in which the calcium repletion model of Liu and co-workers ${ }^{10}$ was revisited to show that the rapid loss of osteoclasts from the bone surface in these animals was associated with apoptosis. ${ }^{17}$

\section{REGULATION OF OSTEOCLAST APOPTOSIS}

\section{Methods used to study osteoclast apoptosis}

The study of osteoclast apoptosis has been complicated by the comparative rarity of this cell type and the short duration of morphologically recognisable apoptosis. It is also difficult to isolate large numbers of osteoclasts in vitro and it is impossible to achieve a $100 \%$ pure population of these cells. However, a characteristic feature of the osteoclast is that it continues to express TRAP strongly during apoptosis (fig $1 \mathrm{~b}$ and $\mathrm{c}$ ). Of the cells normally present in bone marrow, only the osteoclast strongly expresses TRAP. ${ }^{18}$ This ensures that apoptotic osteoclasts can be identified readily in tissue sections and in vitro, thus facilitating the development of techniques for studying osteoclast apoptosis quantitatively both in vivo and in vitro. ${ }^{19}$ This morphological approach was validated by using other techniques for detecting apoptosis, namely DNA strand end-labelling and acridine orange staining. ${ }^{13} 19$ Furthermore, some established techniques used to study bone resorption and osteoclast formation in vitro may indirectly measure osteoclast survival. For example, bone resorption occurring in an ex vivo bone resorption assay using neonatal mouse calvariae reflects osteoclast survival, rather than osteoclast recruitment or activation, after the first 24 hours of culture. ${ }^{20}$ In addition, IL-1 and M-CSF have been shown to prolong the survival of cultured 


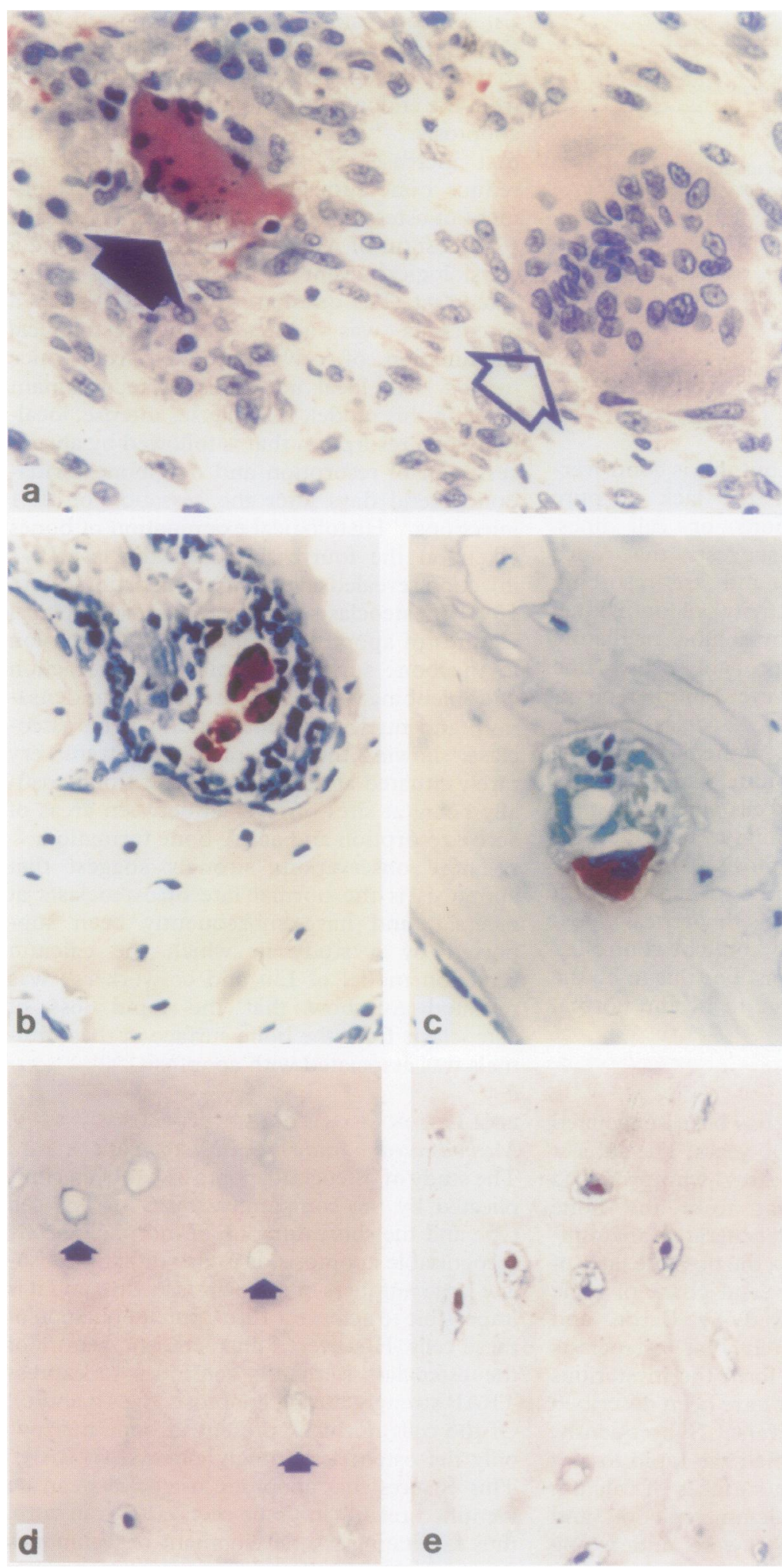

Figure 1 Examples of cell death occurring in bone. (a-c) Osteoclast apoptosis. (a) Histology from a giant cell tumour of bone demonstrating an apoptotic osteoclast (solid arrow) with a viable osteoclast (open arrow) for comparison. The apoptotic cell shows the chromatin condensation, nuclear fragmentation, and cytoplasmic contraction typical of apoptosis. (b) Apoptotic osteoclast stained for tartrate resistant acid phosphatase (TRAP, red cytoplasmic staining), with a similarly stained viable osteoclast in (c) for comparison. In addition to the features of apoptosis demonstrated in (a), the apoptotic osteoclast shows detachment from the bone surface and cytoplasmic fragmentation. (d,e) Osteocyte death.

(d) Subchondral bone from a hip joint affected by osteoarthrosis. The majority of osteocyte lacunae (arrows) are empty. In contrast, osteocytes can be seen in the majority of lacunae in subchondral bone from a normal hip (e). The mechanism leading to the apparent loss of osteocytes in osteoarthrosis is unknown. $(a, d, e)$ Haematoxylin and eosin.

(b,c) TRAP/haematoxylin; all original magnification $\times 400$.

osteoclasts, possibly through the suppression of apoptosis, ${ }^{21}$ as osteoclasts appear to be prone to die by apoptosis in vitro. ${ }^{1122-25}$
Effects of calcitropic hormones and cytokines on osteoclast apoptosis

The techniques referred to have been used to study the regulation of osteoclast apoptosis by a variety of calcitropic hormones and cytokines. In general, factors that stimulate bone 3 resorption inhibit osteoclast apoptosis and fac- $\frac{\text { 음 }}{7}$ tors that inhibit bone resorption promote osteoclast apoptosis. There are exceptions_. calcitonin, which inhibits bone resorption, does $\overrightarrow{\vec{F}}$ not affect osteoclast apoptosis, ${ }^{22}$ an observationo that is in keeping with the reversibility of this으 hormone's action. ${ }^{26}$ Current knowledge of the $\frac{\bar{m}}{\bar{T}}$

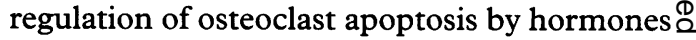
and cytokines is detailed in table 2 . These data suggest that regulation of osteoclast apoptosis $\overrightarrow{0}$ may account, at least in part, for the mechanism by which these factors regulate bone $\vec{\sigma}$ resorption, particularly in the case of cytokines such as IL-1 and TNF $\alpha$.

Effects of oestrogen on osteoclast apoptosis

Perhaps the most interesting of the observa- $N$ tions listed in table 2 is that the oestrogen, $17 \beta$-oestradiol $\left(\mathrm{E}_{2}\right)$, promotes osteoclast apop- $\vec{c}$ tosis both in vitro and in vivo in ovariectomised mice. ${ }^{27}$ Similarly, the oestrogen agonist $/ \vec{\Phi}$ antagonist tamoxifen, which has oestrogenic effects in bone, promotes osteoclast apoptosis in vitro. ${ }^{25} 2728$ The implication of this observa-O tion is that promotion of osteoclast apoptosis may be the mechanism by which $\mathrm{E}_{2}$ inhibits bone resorption in post-menopausal osteo- $\frac{\mathrm{D}}{\mathrm{D}}$ porosis, and conversely that a failure of apoptosis may, at least in part, account for the $\frac{\vec{O}}{3}$ increased osteoclast activity seen in post- $\vec{T}$ menopausal osteoporosis. Although there is ato present no direct evidence to support the latter hypothesis, there is growing evidence that? cytokines such as $\mathrm{TNF} \alpha$, IL-1, IL-6, and 3 M-CSF mediate the increased osteoclast number and bone resorption that follow 3 oestrogen withdrawal. ${ }^{29-31}$ All of these factors 0 inhibit osteoclast apoptosis in vitro ${ }^{11}{ }^{32}$ (Hughes and Boyce, 1995 unpublished observations. There is, however, persuasive evidence that oestrogens can influence osteoclast formation. Bone marrow from ovariectomised mice gave $N$ rise to greater numbers of osteoclasts in ex vivo $\omega$ cultures than did marrow from sham operated animals, and this effect was reversed by oestro- $\stackrel{0}{-}$ gen treatment. ${ }^{31}$ Study of oestrogen treated $\stackrel{\mathbb{P}}{\rightarrow}$ murine marrow cultures revealed that, in addi- 0 tion to an increase in osteoclast apoptosis,

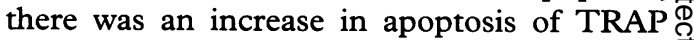
positive mononuclear cells (Hughes and $\underset{\Omega}{\mathbb{\Phi}}$ Boyce, 1995 unpublished observations). The precise identity of these cells is not certain but $O$ it is possible that they represent committed osteoclast precursors. This suggests that oestrogens may also reduce osteoclast formation by depletion of their precursors; this is supported by studies showing that oestrogens can increase apoptosis in mixed bone marrow preparations ${ }^{33}$ and that $\mathrm{E}_{2}$ and an oestrogen agonist (CP-336,156) inhibited osteoclast formation by an apoptotic mechanism. ${ }^{34}$ 
Table 2 Regulation of osteoclast apoptosis

\begin{tabular}{lll}
\hline & Effect on osteoclast apoptosis & \\
\cline { 2 - 3 } Factor & In vitro & In vivo \\
\hline Hormones & & \\
Parathyroid hormone & Inhibits & Unknown \\
$1,25 D$ & Inhibits & Unknown \\
Calcitonin & No effect & Unknown \\
Corticosteroids & Stimulates & Unknown \\
$17 \beta-$-oestradiol & Stimulates & Stimulates \\
Testosterone & Stimulates & Stimulates \\
Cytokines & & \\
M-CSF & Inhibits & Unknown \\
IL-1 & Strongly inhibits & Unknown \\
TNF $\alpha$ & Strongly inhibits & Unknown \\
IL-6 & Inhibits (when combined with its & Unknown \\
TGF $\beta$ & soluble receptor) & \\
Drugs & Stimulates & Stimulates \\
Bisphosphanates & & \\
Tamoxifen & Strongly stimulates & Strongly stimulates \\
RGD peptides (antagonistic to & Stimulates & Unknown \\
$\alpha_{v} \beta_{3}$ integrin) & Stimulates & Unknown \\
\hline
\end{tabular}

1,25D, 1,25-dihydroxyvitamin $\mathrm{D}_{3}$; M-CSF, macrophage-colony stimulating factor; IL, interleukin; TNF, tumour necrosis factor; TGF, transforming growth factor.

\section{Osteoclast-matrix interactions and osteoclast survival}

When deprived of attachment to their normal substrate, many types of cell die by apoptosis, a process that has been termed anoikis. ${ }^{35}$ The osteoclast may be no exception to this. Before undergoing apoptosis at sites of reversal within BMU, osteoclasts lose attachment to the bone surface. ${ }^{16}$ This may not be coincidental, as osteoclasts cultured on dentine slices have a lower basal frequency of apoptosis than controls cultured on plastic, and are more resistant to induction of apoptosis by bisphosphonates. ${ }^{19}$ In addition, integrin specific inhibitory peptides can induce osteoclast apoptosis, particularly those that are specific to the major osteoclast integrin, $\alpha_{v} \beta_{3}$ integrin (the classical vitronectin receptor). ${ }^{36}$ Whether this results from inhibition of matrix attachment or a more direct receptor-ligand interaction remains to be determined.

\section{Pharmacological stimulation of osteoclast} apoptosis: effects of bisphosphonate drugs Bisphosphonates are well known inhibitors of bone resorption. They are used in the treatment of Paget's disease of bone, hypercalcaemia of malignancy, and osteoporosis. ${ }^{37}$ The mechanism of action of these drugs has not been fully clarified. Both in vitro and in vivo studies have revealed that bisphosphonates promote osteoclast apoptosis. ${ }^{192}$ This supports the concept that promotion of osteoclast apoptosis may be an effective strategy in treating diseases of increased bone resorption such as post-menopausal osteoporosis. The underlying mechanism of this effect is not known.

Biochemical mechanisms of osteoclast apoptosis The underlying mechanisms controlling osteoclast apoptosis are currently unknown and will doubtless be the subject of future study. Preliminary studies suggest that transforming growth factor (TGF) $\beta$ may be important in the action of oestrogen, as the effect of $E_{2}$ on osteoclast apoptosis could be reversed by a pan-specific anti-TGF $\beta$ antibody. ${ }^{27}$ There is also evidence that osteoclast-matrix interac- tions could be important in mediation of osteoclast apoptosis. Loss of adhesion of osteoclasts to the bone surface is also a feature that has been described in oestrogen treated animals. ${ }^{38}$ Study of the subcellular mechanisms controlling osteoclast adhesion may therefore provide clues to the pathways controlling apoptosis.

\section{Cell death in the osteoblast lineage}

There is now growing research interest into apoptosis in cells of the osteoblast lineage (bone marrow stroma derived osteoblast precursors, lining cells, and osteocytes). The osteocyte is a very stable and long lived cell and under normal circumstances the fate of osteocytes in bone that is being resorbed is to be phagocytosed by osteoclasts. ${ }^{39}$ Phagocytosed osteocytes typically show the morphological features of apoptosis and thus this is likely to be their fate before or during phagocytosis. ${ }^{27}$ However, recent evidence has been presented that apoptosis can be demonstrated in osteocytes in human bone undergoing high rates of turnover, and that this may signal the onset of resorption. ${ }^{40}$ Furthermore, there is evidence that reduction in oestrogen concentrations in premenopausal women can lead to loss of osteocytes. ${ }^{41}$ Osteocytes are certainly known to disappear from ischaemic bone, as seen in avascular necrosis, but presumably this is by necrotic cell death. Loss of osteocytes has also been described in associated with osteoarthrosis (fig $1 \mathrm{~d}$ and e), although the mode of cell death in this situation has not been established. Whether the loss of osteocytes contributes significantly to changes in bone remodelling following oestrogen withdrawal awaits further study. The presence of morphologically apoptotic osteoblasts at active bone forming seams in normal human bone or bone from genetically unmanipulated mice appears to be an extremely uncommon occurrence in the experience of the authors. However, a recent study ${ }^{43}$ showed that it was possible to demonstrate terminal deoxynucleotidyl transferase dependent nucleotide incorporation into active osteoblasts. This is a phenomenon that can be demonstrated in apoptotic cells, although this technique correlates variably with apoptotic morphology in some cell types, ${ }^{44}$ and on its own cannot be regarded as definitive evidence of apoptosis. Increasingly, the regulation of apoptosis in osteoblast-like cells is being studied in vitro, with evidence of regulation by growth factors and cytokines. ${ }^{43}{ }^{45} 46$ However, because of the lack of certainty of which stage of the osteoblast lineage each particular in vitro model corresponds to, the significance of these observations to osteoblast function and the pathogenesis of bone disease is uncertain. Osteoblast apoptosis has been unequivocally demonstrated in vivo in one setting. Rats of the $t l$ strain are known to have defective osteoblast function and lose osteoblasts from their bone surfaces, which has recently been demonstrated to be due to apoptosis. This was correlated to a defect in the ability of their osteoblasts to assemble actin stress fibres when in contact with the bone surface. ${ }^{47}$ 
Relevance of cell death to bone disease GROWTH PLATE CHONDROCYTE APOPTOSIS Whether abnormalities of chondrocyte death contribute to the pathogenesis of any of the forms of epiphysial dysplasia is not certain. One recent piece of evidence suggests hypertrophic chondrocyte apoptosis may be important in growth plate ossification. ${ }^{48}$ Hypertrophic chondrocytes overexpressing a mutated form of the fibroblast growth factor receptor FGFR3, which has ligand independent tyrosine kinase activity, as happens in achondroplastic dwarfism, were more resistant to apoptosis. This suggests that apoptosis of hypertrophic chondrocytes has a permissive role in growth plate ossification.

\section{OSTEOCLAST APOPTOSIS}

The aforementioned studies of osteoclast apoptosis have been almost exclusively in animal models, therefore, the contribution of changes in the regulation of osteoclast apoptosis to the pathogenesis of bone disease can only be speculated. Human osteoclasts certainly can undergo apoptosis, having been observed in bone from patients with osteoarthrosis, hyperparathyroidism, and Paget's disease (Hughes and Boyce, 1995 unpublished observations). It can also be seen readily in osteoclast rich lesions such as giant cell tumours of bone and tendon sheath and aneurysmal bone cysts (Hughes and Boyce, 1995 unpublished observations; Salter and Reid, 1995 personal communications) (fig 1a). The observation of apoptotic osteoclasts in these situations is possible because of the abnormally large numbers of osteoclasts present. Because of the short duration of apoptosis (as little as one hour in some cell types) and the relative rarity of osteoclasts in normal bone, the probability of observing an osteoclast in apoptosis by chance in normal human bone is extremely small. While it is theoretically possible that in some diseases characterised by increased bone resorption (Paget's disease of bone, hyperparathyroidism, and post-menopausal osteoporosis) there is relative inhibition of osteoclast apoptosis, this hypothesis is impossible to test using currently available techniques. However, it is noteworthy that bisphosphonates, which are effective therapeutic agents in Paget's disease of bone and post-menopausal osteoporosis, promote osteoclast apoptosis not only in rodents ${ }^{19}$ but also in humans (Boyce and Hughes, 1996 unpublished observations).

\section{APOPTOSIS IN THE OSTEOBLAST LINEAGE}

Currently, the only evidence to suggest that apoptosis of any cells of the osteoblast lineage is an aetiological factor in any form of bone disease is a study by Dunstan and co-workers who found empty osteocyte lacunae more frequently in femoral heads from elderly subjects than from young subjects. ${ }^{49}$ They did not comment on osteocyte apoptosis as the possible cause of the disappearance of osteocytes from these bones, but osteocyte apoptosis in the proximal femur could perhaps be linked in some way to the increase in fragility of bone at this site in the elderly. Osteocyte death has also been reported in osteoarthrosis, but this is perhaps more likely to represent a consequence rather than a cause of the disease. Loss of normal function of p53 and the retinoblastoma gene are strongly associated with the pathogenesis of osteosarcoma through a variety of lines of evidence..$^{50-52}$ When the function of these two 으 genes is lost simultaneously there is evidence that cell proliferation outweighs apoptosis. ${ }^{53}$ However, the significance of this to the development of osteosarcomas is unknown.

\section{Conclusions}

Although cell death in bone may have been described almost 100 years go, its possible role in bone physiology and pathology has been $\mathrm{s}$ largely ignored until recently. Even now, the $\vec{\circ}$ level of knowledge and understanding of cell $\overrightarrow{\vec{\omega}}$ death in the osteoclast and osteoblast lineages $\stackrel{\sigma}{\omega}$ is rather limited because of the difficulty of studying this process, particularly in vivo. if However, there is now increasing evidence to suggest that, at least in the osteoclast lineage, changes in the regulation of cell death may $\underset{N}{\omega}$ contribute to clinically important diseases of bone such as post-menopausal osteoporosis, and that the induction of osteoclast apoptosis is $\check{c}$ a potential therapeutic tool for treating these $\mathbb{D}$ diseases.

Much of the work on osteoclast apoptosis that is described in this article was facilitated by the excellent technical work of Beryl Story and Arlene Farias. Work relating to cell death in bone in the laboratory of BFB has been funded by National Institutes of Health grants AR 43510, AR 39529, and DK 45299 , and by a grant from the Center for the Enhancement of the Biology/Biomaterials Interface (CEBBI). DEH was the Ine 0 作 Fellowship while carrying out some of this work.

1 Frost HM. The laws of bone structure. Spingfield: Charles $\mathrm{C}$ Thomas, 1964

2 Baron R, Vignery A, Horowitz M. Lymphocytes, macrophages and the regulation of bone remodelling. In: Peck WA, ed. Bone and mineral research 2. Amsterdam: Elsevier, 1983:175-243.

3 Roach HI, Erenpreisa J, Aigner T Osteogenic differentiation of hypertrophic chondrocytes involves asymmetric cell of hypertrophic chondrocytes involves asymmetric
divisions and apoptosis. $\mathcal{F}$ Cell Biol 1995;131:483-94.

4 Williams GT, Smith CA. Molecular regulation of apoptosis: genetic controls on cell death. Cell 1993;74:777-9.

5 Hale AJ, Smith CA, Sutherland LC, Stoneman VEA, Longthorne VL, Culhane AC, et al. Apoptosis: molecular regulation of cell death. Eur F Biochem 1996;236:1-26.

6 Mundy GR, Roodman GD. Osteoclast ontogeny and function. In: Peck $\mathrm{W}$, ed. Bone and mineral research $V$. O tion. In: Peck W, ed. Bone and

7 McSheehy PMJ, Chambers TJ. Osteoblastic cells mediate $N$ osteoclastic responsiveness to parathyroid hormone. Endo- $N$ crinology 1986;118:824-8.

8 Thomson BM, Saklatvala J, Chambers TJ. Osteoblasts mediate interleukin-1 responsiveness of bone resorption by rat osteoclasts. $\mathcal{F} \operatorname{Exp}$ Med 1986;164:104-12.

9 Arey LB. The origin, growth and fate of osteoclasts and their relation to bone resorption. American fournal of Anatomy 1920;26:315-45.

(T) in C-C, Rader JI, Gruber H, Baylink DJ. Acute reduction in osteoclast number during bone repletion. Metab Bone

11 Fuller K, Owens JM, Jagger CJ, Wilson A, Moss R, Cham- $\frac{\cap}{\mathbb{D}}$ bers TJ. Macrophage colony-stimulating factor stimulates $\varrho$ survival and chemotactic behaviour in isolated osteoclasts. f Exp Med 1993;178:1733-44.

12 Boyce BF, Windle JJ, Reddy SV, Wright K, Leach RJ, Roodman GD. Targeting SV-40 T antigen to the osteoclast in transgenic mice causes osteopetrosis, transformation and apoptosis of osteoclasts [abstract]. 7 Bone Miner Res 1993; 8(Suppl):S118.

13 Boyce BF, Wright K, Reddy SV, Koop BA, Story B, Devlin $\mathrm{R}$, et al. Targeting simian virus $40 \mathrm{~T}$ antigen to the $\mathrm{R}$, et al. Targeting simian virus $40 \mathrm{~T}$ antigen to the osteoclast in transgenic mice causes osteoclast tumors and transformation and apoptosis of osteoclasts. Endocrinology

4 Gavrieli Y, Sherman Y, Ben-Sasson SA. Identification of programmed cell death in situ via specific labeling of nuclear DNA fragmentation. $\mathcal{f}$ Cell Biol 1992;119:493501 
15 Boyce BF, Aufdemorte TB, Garrett IR, Yates AJP, Mundy GR. Effects of interleukin-1 on bone turnover in normal mice. Endocrinology 1989;125:1142-50.

16 Wright KR, Hughes DE, Guise TA, Boyle IT, Devlin R, Windle J, et al. Osteoclasts undergo apoptosis at the interface between resorption and formation in bone remodelling units [abstract]. F Bone Miner Res 1994;9(Suppl): S174

17 Wright KR, McMillan PJ, Hughes DE, Boyce BF. Calcium deficiency/repletion in rats as an in vivo model for the study of osteoclast apoptosis. F Bone Miner Res 1995;10(Suppl): S328.

18 Minkin C. Bone acid phosphatase: tartrate-resistant acid phosphatase as a marker of osteoclast function. Calcif Tissue Int 1982;34:285-90.

19 Hughes DE, Wright KR, Uy HL, Sasaki A, Yoneda T, Roodman GD, et al. Bisphosphonates promote apoptosis in murine osteoclasts in vitro and in vivo. 7 Bone Miner Res murine osteoclasts

20 Garrett IR, Mundy GR. Relationship between interleukin-1 and prostaglandins in resorbing neonatal calvaria. $\mathcal{F}$ Bone Miner Res 1989;4:789-94.

21 Jimi E, Shuto T, Koga T. Macrophage colony-stimulating factor and interleukin-1a maintain the survival of osteoclast-like cells. Endocrinology 1995;136:808-11.

22 Hughes DE, Wright KR, Sasaki A, Yoneda T, Uy H, Roodman GD, et al. Bisphosphonates induce osteoclast apoptosis in vivo and in vitro, but calcitonin does not [abstract]. $f$ sis in vivo and in vitro, but calcitonin
Bone Miner Res 1994;9(Suppl):S347.

23 Selander KS, Monkkonen J, Karhukorpi E-K, Harkonene P, Hannuniemi R, Vaananen HK. Characteristics of clodronate-induced apoptosis in osteoclasts and macrophages. Mol Pharmacol 1996;50:1127-38.

24 Kameda T, Ishikawa H, Tsutsui T. Detection and characterization of apoptosis in osteoclasts in vitro. Biochem Biophys Res Commun 1995;207:753-60.

25 Lutton JD, Moonga BS, Dempster DW. Osteoclast demise in the rat: physiological versus degenerative cell death. Exp Physiol 1996;81:251-60.

26 Chambers TM, Magnus CJ. Calcitonin alters behaviour of isolated osteoclasts. $\mathcal{F}$ Pathol 1982;136:27-39.

27 Hughes DE, Dai, A, Tiffee JC, Li HH, Mundy GR, Boyce BF. Estrogen promotes apoptosis of murine osteoclasts mediated by TGF- $\beta$. Nature Medicine 1996;2:1132-6.

28 Arnett TR, Lindsay R, Kilb JM, Moonga BS, Spowage M, Dempster DW. Selective toxic effects of tamoxifen on osteoclasts: Comparison with the effects of oestrogen. $\mathcal{F}$ Endocrinol 1996;149:503-8.

29 Horowitz MC. Cytokines and estrogen in bone; antiosteoporotic effects. Science 1993;260:626-7.

30 Pacifici R. Is there a causal role for IL-1 in postmenopausal bone loss? Calcif Tissue Int 1992;50:295-9.

31 Jilka RL, Hangoc G, Girasole G, Passeri G, Williams DC, Abrams JS, et al. Increased osteoclast development after estrogen loss: mediation by interleukin-6. Science 1992;257: $88-91$.

32 Hughes DE, Wright KR, Mundy GR, Boyce BF. TGFß1 induces osteoclast apoptosis in vitro [abstract]. $\mathcal{F}$ Bone Miner Res 1994;9(Suppl):S138.

33 Shevde NK, Pike JW. Estrogen modulates the recruitment of myelopoietic cell progenitors through a stromal cellindependent mechanism involving apoptosis. Blood 1996; 87:2683-92.

34 Grasser WA, Mansolf AL, Pirie CM, Cameron KO, Toler SM, Rosati RL, et al. CP-336,156 and estrogen identically inhibit osteoclastogenesis in rat bone marrow cultures through an apoptotic mechanism [abstract]. $\mathcal{f}$ Bone Miner Res 1996;11(Suppl):S397.

35 Ruoslahti E, Reed JC. Anchorage dependence, integrins, and apoptosis. Cell 1994;77:477-8.
36 Hughes DE, Wright KR, Mundy GR, Boyce BF. Association of osteoclast apoptosis with loss of adhesion [abstract]. F Bone Miner Res 1995;10(Suppl):S326.

37 Fleisch H. Bisphosphonates in bone disease: From the laboratory to the patient. 2nd edn. New York: Parthenon Publishing Group, 1995.

38 Liu C-C, Howard GA. Bone-cell changes in estrogeninduced bone-mass increase in mice: Dissociation of osteoclasts from bone surfaces. Anat Rec 1991;229:240-50.

39 Elmardi AS, Katchburian MV, Katchburian E. Electron microscopy of developing calvaria reveals images that suggest that osteoclasts engulf and destroy osteocytes during bone resorption. Calcif Tissue Int 1990;46:239-45.

40 Noble BS, Stevens H, Reeve J, Loveridge N. Apoptosis in normal and pathological human bone [abstract]. F Bone Miner Res 1995;10(Suppl):S217.

41 Tomkinson A, Reeve J, Shaw RW, Noble BS. The death of osteocytes via apoptosis accompanies oestrogen withdrawal in human bone [abstract]. F Bone Miner Res 1996; 11(Suppl):S129.

42 Wong SYP, Evans RA, Needs C, Dunstan CR, Hills E Garvan J. The pathogenesis of osteoarthritis of the hip. Evidence for primary osteocyte death. Clin Orthop Rel Res 1987;214:305-12.

43 Jilka RL, Weinstein RS, Bellido T, Miller FL, Smith C, Parfitt $\mathrm{AM}$, et al. Demonstration of programmed cell death (apoptosis) in osteoblasts: evidence for modulation of this process by growth factors and cytokines [abstract]. $\mathcal{F}$ Bon Miner Res 1996;11(Suppl):S144.

44 Wright KR, Story B, Hughes DE, Windle J, Reddy S, Roodman GD, et al. Standard morphology is more sensitive than TUNEL for identification of apoptosis in osteoclasts [abstract]. F Bone Miner Res 1995;10(Suppl):S324.

45 Machwate M, Rodan SB, Rodan GA, Harada S. Prostaglandin (PG) $\mathrm{E}_{2}$ suppresses apoptosis in two rat periosteal cell lines via a cAMP-dependent pathway [abstract]. $\mathcal{F}$ Bone Miner Res 1996;11(Suppl):S143.

46 Nuttall ME, Gowen M. Human osteosarcoma (HOS TE-85) cells undergo an apoptotic process that is inhibited by IGF-1 [abstract]. I Bone Miner Res 1996;11(Suppl): by IG

47 Watanabe H, MacKay C, Kislauskis E, Mason-Savas A, Marks SC Jr. The cytoskeleton, cell attachment and survival of osteoblasts in osteopetrotic (tl) rats [abstract]. $\mathcal{F}$ Bone Miner Res 1996;11(Suppl):S172.

48 Henderson JE, Naski M, Ornitz DM, Goltzman D, Karaplis AC. Expression of FGFR3 carrying the G380R achondroplasia mutation in rodent chondrocytes: effects on proliferation, differentiation and apoptosis [abstract]. $\mathcal{F}$ Bone Miner Res 1996;11(Suppl):S103.

49 Dunstan CR, Evans RA, Hills E, Wong SY, Higgs RJ. Bone death in hip fracture in the elderly. Calcif Tissue Int 1990;47:270-5.

50 Scholz RB, Kabisch H, Weber B, Roser K, Delling G, Winkler K. Studies of the RB1 gene and the 553 gene in human osteosarcomas. Paediatric Hematol Oncol 1992;9:125-37.

51 Radinsky R, Fidler IJ, Price JE, Esumi N, Tsan R, Petty $\mathrm{CM}$, et al. Terminal differentiation and apoptosis in experimental lung metastases of human osteogenic sarcoma cells by wild type p53. Oncogene 1994;9:1877-83.

52 Miller CW, Aslo A, Won A, Tan M, Lampkin B, Koeffler $\mathrm{HP}$. Alterations of the $\mathrm{p} 53, \mathrm{Rb}$ and MDM 2 genes in osteosarcoma. F Cancer Res Clin Oncol 1996;122:559-65.

53 Almasan A, Yin Y, Kelly RE, Lee EY, Bradley A, Li W, et al. Deficiency of retinoblastoma protein leads to inappropriate S-phase entry, activation of E2F-responsive genes, and apoptosis. Proc Natl Acad Sci USA 1995;92:5436-40. 